OPEN ACCESS

Edited by:

Vladan Starcevic, University of Sydney,

Australia

Reviewed by:

Marco Di Nicola,

Università Cattolica del

Sacro Cuore, Italy

Artemis Kimon Tsitsika, Adolescent Health Unit (AHU),

Greece

*Correspondence:

Xavier Benarous xavier.benarous@aphp.fr

Specialty section:

This article was submitted to

Addictive Disorders,

a section of the journal

Frontiers in Psychiatry

Received: 09 October 2018

Accepted: 29 April 2019

Published: 10 May 2019

Citation:

Benarous $X$, Morales $P$, Mayer $H$, lancu $C$, Edel $Y$ and Cohen D (2019) Internet Gaming Disorder in Adolescents With Psychiatric Disorder: Two Case Reports Using a Developmental Framework.

Front. Psychiatry 10:336. doi: 10.3389/fpsyt.2019.00336

\section{Internet Gaming Disorder in Adolescents With Psychiatric Disorder: Two Case Reports Using a Developmental Framework}

\author{
Xavier Benarous ${ }^{1,2 *}$, Pierre Morales ${ }^{3}$, Hanna Mayer $^{1}$, Cosmin lancu ${ }^{1}, Y_{v e s}$ Edel $^{3}$ \\ and David Cohen ${ }^{1,4}$ \\ ${ }^{1}$ Department of Child and Adolescent Psychiatry, Pitié-Salpêtrière Hospital, Paris, France, ${ }^{2}$ INSERM Unit U1105 Research \\ Group for Analysis of the Multimodal Cerebral Function, University of Picardy Jules Verne (UPJV), Amiens, France, \\ ${ }^{3}$ Department of Addiction, Hôpital Pitié-Salpêtrière, Paris, France, ${ }^{4}$ CNRS UMR 7222, Institute for Intelligent Systems \\ and Robotics, Sorbonnes Université, Paris, France
}

Internet gaming disorder (IGD) has been a controversial entity with various opinions about its clinical relevance as an independent mental disorder. This debate has also included discussions about the relationships between problematic gaming, various psychiatric disorders, and personality traits and dimensions. This paper outlines a developmentaltheory based model of Internet gaming misuse inspired by the treatment of two adolescent inpatients. The two clinical vignettes illustrate distinct developmental pathways: an "internalized pathway" via the development of social anxiety, emotional and behavioral avoidance; and an "externalized pathway" with a low level of emotional regulation strategies and impulsivity. In both clinical cases, attachment issues played a key role to understand the specific associations of risk and maintaining factors for IGD, and gaming behaviors may be seen as specific forms of maladaptive self-regulatory strategies for these two youths. These clinical observations support the assumption that gaming use problematic in adolescents should be viewed with a developmental approach, including key aspects of emotional development that represent significant targets for therapeutic interventions.

Keywords: Internet gaming disorder, gaming misuse, internalizing disorders, externalizing disorders, behavioral addiction, emotional dysregulation, insecure attachment, adolescents

\section{BACKGROUND}

\section{Internet Gaming Disorder}

In 2013 the American Psychiatric Association included the Internet gaming disorder (IGD) in the research appendix of the Diagnostic and Statistical Manual, Fifth Edition (DSM-5) recommending that further studies be conducted (1). Following DSM-5 suggestions, gaming disorder (GD) was recently included as a formal diagnostic entity in the 11th edition of the International Classification of Diseases (2) referring to both offline and online games and drawing a distinction between GD and hazardous gaming. The prevalence of IGD/GD is estimated between $1.2 \%$ and $5.5 \%$ in teenagers, and a problematic gaming use would concern about 1 out of 10 adolescents playing video games (3). 
Many concerns have been raised about the identification of the DSM-5 IGD or the CIM-11 GD as discrete clinical entities (4-6). Authors haveidentified several problems focusing on the diagnostic criteria and their conceptual and empirical issues. These includes the validity of the current diagnostic criteria, the broadening of the disorder to include Internet non-gaming activities (e.g., social media), and the risk of overpathologizing a common activity $(3,6$, 7). All that aside, empirical studies have shown that persistent or recurrent gaming behavior is associated with a broad spectrum of psychopathology in adolescents such as social anxiety, depressive disorder, attention deficit disorder, conduct disorder, substancerelated addictive disorder, and pathological personality traits (3, $5)$. These findings are consistent among researches conducted in community-based samples (8-12), Internet-recruited youths (13), and help-seeking populations $(14,15)$.

Longitudinal studies have supported a bidirectional relation between IGD and mental health problems in adolescents (16-18), e.g., psychopathological traits, such as impulsivity, increase the risk for IGD; in turn, the time of gaming exposure predicts the severity of depressive symptoms 2 years later in adolescents (16).

\section{A Developmental-Based Model of Internet Gaming Misuse in Adolescents}

Adolescence represents a period of vulnerability for the emergence of addictive behaviors with a peak of the incidence during the transition into young adulthood (19). Developmentally, teens are focused on establishing autonomy and identity through sets of social experiences within peer groups. The need to integrate multiple, and somewhat conflicting, demands and developmental needs may result in interpersonal conflicts and emotional distress (20). In this context, addictive behaviors can emerge as a means of developing a new sense of identity within a peer group and relieve emotional distress (21). While the starting point of addictive behavior is often during adolescence, etiological factors are rooted in childhood, especially early-environmental factors and cognitive and socio-emotional dysfunctions $(19,22,23)$.

Such as operationalized in the DSM-5, the definition of IGD eludes any developmental perspectives. How do the clinical significance, the natural course, and the therapeutic strategies for IGD vary across age? Indeed, one may think that the impact of severe gaming misuse will depend on how this behavior interferes with normal developmental changes observed at the biological (e.g., cerebral maturation), cognitive (e.g., emotion regulation, motor inhibition), psychological (e.g., identity formation and social roles construction), and environmental (e.g., academic/ professional success, peer and family relationship) levels in a specific time window. The developmental view focuses more specifically on when and how such that vulnerability factors interfere and may form distinct susceptibility pathways to gaming misuse and/or psychopathology.

\section{Youths With Severe Psychiatric Disorders}

Most of the literature devoted to severe gaming misuse in adolescents comes from studies conducted in general populations, Internet-recruited samples, or outpatient clinics. Only anecdotal reports exist concerning youths with severe psychiatric disorders $(14,24)$. However, in this last group, the aggregation of academic problems, social withdrawal, and the severity of internalized symptoms puts them at very high risk of developing gaming misuse. Moreover, if Internet gaming misuse alters the course of psychiatric symptoms in youths with severe psychiatric disorders, recognizing and treating dual diagnoses would represent a clinically relevant proposal.

\section{Aims}

In this paper, we aimed to describe two case reports of IGD in adolescents with severe psychiatric disorder using a developmental approach. We sought to present different interplays between gaming behavior, psychopathology, and environment. The developmental pathways underlying the association of risk and maintaining factors are discussed for each vignette with regards to existing literature about Internet gaming misuse in adolescents.

\section{METHODS}

This study is part of a larger research on the relationship between addictive disorders and psychopathology among adolescents with severe psychiatric disorder (25). Participants are adolescents (12-18 years old) hospitalized in the Department of Child and Adolescent Psychiatry at the Pitié-Salpêtrière University Hospital in Paris. Vignettes have been selected by the psychiatric team and the hospital's liaison addiction unit. In the remainder of this article, we have used the DSM-5 classification to refer to problematic GD and psychiatric disorders. Written informed consent was obtained from the parents/legal guardians for the publication of these cases. Presentation of the case reports follows the CARE Guideline (26).

\section{CASE PRESENTATION 1}

\section{Patient Information and Clinical Findings}

A was a 13-year-old boy referred to the inpatient unit for severe social withdrawal with school dropout since a year and a half. He had no prior psychiatric or medical history. He lived with his identical twin sister and his mother. The father had died 2 years ago from lung cancer. The twins were born prematurely at 34 weeks, but no delay in psychomotor acquisitions was reported.

Following the death of his father, A started to develop isolation and social withdrawal. Around the same period, he started playing at a construction game on his computer. The time spent in this activity increased, and the patient gave up school and other activities. Over the past year, A played 10 to $12 \mathrm{~h}$ per day with no period free of playing longer than 1 day. When not gaming, A was irritable, vindictive, and verbally aggressive. In addition, gaming did not involve any socializing aspects (e.g., forum or online competition). During the last 6 months, he was completely confined to his room (except for personal hygiene) spending almost all of the daytime playing the video game. All the family's attempts to help him reduce gaming failed. The patient actively refused to meet mental health professionals, and during home visits, he stayed locked in his room. 


\section{Diagnostic and Psychopathological Assessment}

At admission, the patient appeared to be a discrete boy. He looked sad and withdrawn with minimal verbal interaction. The speech was monotone and overly soft with many pauses and, in particular, reluctant to talk about his thoughts. A was particularly careful to pick the right word to answer questions. He expressed a pervasive feeling of hollowness and a loss of interest in his surroundings. His mood was poorly influenced by external circumstances. He described the feeling as being emotionally paralyzed rather than sadness. A reported no pessimistic thoughts or feelings of hopelessness; however, he was unable to project himself into the future and had no motivation to perform any activities other than gaming. Sleep and appetite were preserved and no delusion was reported. The diagnosis of persistent depressive disorder (F34.1) was made (1).

Prior to the onset of the current depressive disorder, A experienced socio-emotional and interpersonal difficulties. He shared his emotional experiences only on rare occasions and was reluctant to seek support for basic or emotional needs. As a child he is described as frequently embarrassed in new and unfamiliar situations, with few behavioral strategies to manage his emotion. The restriction of facial and voice affect, initially interpreted as a sign of depressive mood, was reported since an early age.

During medical interviews, A's mother presented poor emotional insight. Her voice and face expressed deep sadness, but she was reluctant to discuss her feelings. Questions about the relations between family grief, the impact on each family member, and A's psychiatric symptoms were eluded. She never mentioned her own social phobia that we discovered long after this hospitalization. In fact, it turned out that the weekly appointments to the adolescent outpatient care service were her only source of relational contacts. About gaming, she felt helpless in monitoring the gaming use. She agreed to receive behavioral guidance but never managed to apply any suggestions. Her motivation to change the current situation at home seemed low.

\section{Therapeutic Interventions, Follow-Up, and Outcomes}

A was treated with an antidepressant, a selective serotonin reuptake inhibitor (SSRI), sertraline up to $75 \mathrm{mg} /$ day. In the ward, he was involved in different activities with other inpatients in view of promoting positive experiences with adults and peers. He seemed more open and talkative with the paramedical staff and with other youths than during the medical interviews. He had a weekly support group and a group for behavioral and substance-related addictive disorders. The patient started school readaptation a few hours per day.

After 4 weeks, the patient felt progressively better. During permissions at home, $\mathrm{A}$ is described as more dynamic and emotionally reactive. He started to enjoy usual interests with other members of the family and actively sought out friendship in planning lunch during the weekend with adolescents met at the hospital. Progressively, he spent less time playing video games (around $2 \mathrm{~h}$ per day) without anxiety when not playing.
Despite the clinical and functional improvement, both A and his mother seemed unable to identify external or internal factors that contributed to A's depressive disorder and gaming misuse. They did not express any worries regarding possible relapse. For both of them, mental projections into the past or the future were nearly impossible or were unrealistic. For example, despite a year and a half without being at school, $\mathrm{A}$ and his mother declined all school adaptations. The patient viewed grade repetition as a source of stigmatization and refused to return to school. Further, therapeutic suggestions such as daily care intervention or individual psychotherapy were politely declined by the patient.

After discharge, the patient had regular appointments in an outpatient care structure and started in a new school. After 10 weeks, the mother contacted us to explain that her son refused to follow outpatient care, no longer attended school, and again had social withdrawal with severe gaming misuse.

\section{CLINICAL RELEVANCE}

\section{Interplay Between Emotional Distress and Gaming Misuse}

In this vignette, anxiety/mood symptoms and Internet gaming misuse are highly correlated: a decrease in the severity of mood symptoms was associated with less gaming behavior, and the "relapse" into severe gaming occurred with the resurgence of emotional distress. Such association has been well demonstrated $(8,10,11)$. In longitudinal studies, pathological video game use is predicted by anxiety (including social phobia) and depressive symptoms $(9,16,17)$. Such bidirectional interplay between gaming misuse and anxiety/mood symptoms can progressively generate an ongoing cycle of internalizing symptoms (18).

\section{Insecure Attachment as a Shared Vulnerability Factor}

Here, we made a diagnosis of associated reactive attachment disorder (F94.1) (1) with regards to A's difficulties to initiate and respond to most social interactions in a developmentally normal way continuously observed since his early childhood. Moreover, a context of caregiving emotional deprivation was very likely considering the difficulties for the mother to recognize and make sense of her own emotions and those of her children.

Among children with insecure attachment style, an anxiousavoidant subtype has been identified (27). These children tend to not exhibit distress on separation and either ignore the caregiver or turned away from him/her on their return. Main (28) suggested that these children actively avoided a consistently unresponsive caregiver in view of avoiding a situation of distress and ultimately maintaining a sense of control. The avoidance of any new relational situation in children with an anxious-avoidant attachment type can lead to poor self-esteem and internalizing symptoms via the lack of opportunities to learn social skills with his/her caregiver (29).

Adolescents and young adults with problematic Internet use are more likely to have an insecure attachment style (3033). An Italian study found that attachment styles contribute 
for a significant proportion (13\%) to the variance in scores of addictive behaviors in college students (33). Some psychological traits reported in this clinical vignette, such as the high-level of psycho-rigidity, mental and interpersonal control, and relational inflexibility, are also reported as a putative risk factor for the onset and maintenance of gaming misuse in adolescents $(3,33)$. One study supports this developmental view, as authors found that attachment/personality traits in young adults mediate the impact of dysfunctional family relationships on the occurrence of IGD (34). In the Discussion, we detail how avoidance and social withdrawal as a persistent maladaptive reaction in a patient with an anxious-avoidant insecure attachment play a key role in the emergence and persistence of the mood disorder and gaming problematic.

\section{CASE PRESENTATION 2}

\section{Patient Information and Clinical Findings}

$B$ was a 15-year-old boy referred to an inpatient unit for severe disruptive behaviors after being expelled from his school. He lived with his 10-year-old younger brother and two half-brothers (aged 20 and 30 years). The parents were separated although living together. B had commonly been exposed to severe arguing and fighting between them. Both parents were unemployed. The father had an untreated alcohol addiction and the mother had no specific past psychiatric history. The family had been followed by social services since B was 3 .

The patient's pregnancy was complicated by gestational diabetes and occasional maternal alcohol intake. $\mathrm{B}$ was born prematurely at 35 weeks of gestation. He had a delayed onset of speech (first words at 2 years) and fine motor difficulties. At entrance in first grade, he had difficulties understanding verbal instructions and performing graphomotor activities. Distractibility and emotional dysregulation were also noted. At age 6, a Wechsler Preschool and Primary Scale of Intelligence (WPPSI-III) test found a heterogeneous functioning in normal range (Verbal IQ $=100$, Performance IQ $=75$ ). At age 7 , the patient was addressed to a foster care family with a full-time inclusion in an educational facility for youths with behavioral problems. Improvement in emotional control was noted.

At age 13, B faced multiple adverse life events (incarceration of his half-brother, left foster care to return to family home, and change in the pedagogic team). He became physically aggressive against peers and adults with several rage outbreaks per day. Different medications were tried with no or partial improvement: tiapridum (a first generation antipsychotic) up to $15 \mathrm{mg} /$ day, carbamazepine up to $200 \mathrm{mg} /$ day, risperidone gradually increased to $4 \mathrm{mg} /$ day. B was excluded from his educational facility following the aggression of a member of the educational staff. Since then, the patient has stayed at home all day. He was described as severely irritable with multi-daily outbursts of uncontrollable anger. He was verbally and physically aggressive against his parents in a context of frustration and tried to strangle a neighbor after a banal remark. During this period, B maintained his interests in his usual activities, for example, caring for animals or cooking.
He drastically increased time on his computer following school expulsion. He mostly played Role-Playing Games and First Person Shooter Games, with violent scenarios. Daily playing sessions lasted 2-6 h, occasionally during the night. He could compulsively watch online videos during several hours, either childish cartoons or violent videos of aggression. B had daily alcohol consumption usually alone of one glass of wine or a can of beer with bingedrinking sessions almost every month (i.e., $10 \mathrm{~g}$ of alcohol each day or 8.75 units per week on average). He explained that alcohol was a means to "calm down." Of note, the patient was very critical of his father's addiction problem, criticizing his father's inability when drunk to care for him. He also had very occasional cannabis use (smoked one joint every 2 months).

\section{Diagnostic and Psychopathological Assessment}

During individual interviews, B was calm. He described a feeling of hostility, persisting anger and ambivalent feelings toward adults ("worry, shame and anger at the same time"). He reported being exposed to violent conflicts at home and frequently having to take care of his drunk father. Globally, he described a situation of physical and emotional neglect at home. B expressed concern about the consequences of his behavior and his future (he wished to become a cook). He was afraid of "being always angry" after leaving the hospital or that similar problems would repeat with his young brother. Sleep and appetite were preserved.

In the unit, he had few contacts with other youths. He was too clumsy to be involved in sport activities and was often rejected by the group when playing board games. He felt more comfortable with younger patients with whom he shared common interest in animals. When he felt worried, the patient sought attention from adults with provocative behaviors or threats. He could suddenly give a blow to a wall, against a window, or against a piece of furniture without any explanation.

Psychomotor assessment showed evidence of a developmental coordination disorder (F82) (1): general motor and coordination test score was at 0.1 percentile, visuomotor integration test score was very low, and he had -7 standard deviations for writing abilities (Table 1). Language evaluation showed evidence of severe dyslexia (Reading disorder, F315.0) with normal to weak abilities in oral language but very deficient reading competency (Table 2). The diagnosis of disruptive mood dysregulation disorder (F34.8) in an adolescent with multiple learning disabilities (developmental coordination disorder, dyslexia, dysgraphia) was set up and explained to the patient and his parents.

\section{Therapeutic Interventions, Follow-Up, and Outcomes}

The treatment with carbamazepine was discontinued and risperidone was decreased to $2 \mathrm{mg} / \mathrm{day}$, a dose more typically used in youths with disruptive behaviors (35). A benzodiazepine, diazepam, was added for its anxiolytic effect. The patient also started a psychomotor rehabilitation in the service (weekly group relaxation and individual sessions). The need for an intensive 
TABLE 1 | Psychomotor assessment performed by B.

\begin{tabular}{|c|c|}
\hline Tasks & Scores \\
\hline \multicolumn{2}{|l|}{ Gross Motor Skills: M-ABC-2 } \\
\hline Manual dexterity sub-score & 14 (1st \%ile) \\
\hline Ball skills sub-score & 14 (16 $\%$ il $\%)$ \\
\hline Static and dynamic balance sub-score & 9 (0.1 $1^{\text {st }} \%$ ile) \\
\hline Total score & 37 (0.1 $1^{\text {st }} \%$ ile $)$ \\
\hline \multicolumn{2}{|l|}{ Gnosopraxis: EMG } \\
\hline Hands movements imitation & $7.5 / 10(-2.98 \mathrm{SD})$ \\
\hline Fingers movements imitation & 3/16 (+0.42 SD) \\
\hline \multicolumn{2}{|l|}{ Bodily Image } \\
\hline GHDT test & $\mathrm{DA}=7.25$ years \\
\hline Berges somatognosia test & Succeed \\
\hline \multicolumn{2}{|c|}{ Visual perception and visual-motor integration skill: DTPV-2 } \\
\hline Motor-reduced visual perception & 36 (32nd \%ile) \\
\hline Visual-motor integration & 27 (27 \%ile) \\
\hline \multicolumn{2}{|l|}{ Graphism } \\
\hline BHK-ado & $37(-7 \mathrm{SD})$ \\
\hline Bender visual-motor test & $\mathrm{DA}=6.0$ years \\
\hline \multicolumn{2}{|l|}{ Rhythm tasks } \\
\hline Auditory-perceptual-motor task (Soubiran) & Failed \\
\hline Auditory-visual-kinesthetic task (Soubiran) & Failed \\
\hline Tapping (Stambak) & Failed \\
\hline \multicolumn{2}{|c|}{$\begin{array}{l}\text { DA, developmental age; SD, standard deviation; M-ABC, Movement Assessment } \\
\text { Battery for Children; EMG, Evaluation de la Motricité Gnosopraxique; GHDT, } \\
\text { Goodenough-Harris Drawing Test; DTPV-2, Developmental Test of Visual Perception } \\
2^{\text {nd }} \text { edition; BHK-ado, Bender test, Bender Visual-Motor Gestalt Test. }\end{array}$} \\
\hline
\end{tabular}

TABLE 2 | Cognitive, oral, and written language assessments performed by B.

\begin{tabular}{|c|c|}
\hline Tasks & Scores \\
\hline \multicolumn{2}{|c|}{ Wechsler intelligence scale for children-IV } \\
\hline \multicolumn{2}{|c|}{ Verbal comprehension index } \\
\hline \multicolumn{2}{|l|}{ Perceptual reasoning index } \\
\hline \multicolumn{2}{|l|}{ Working memory index } \\
\hline \multicolumn{2}{|l|}{ Processing speed index } \\
\hline \multicolumn{2}{|l|}{ Phonology } \\
\hline Repetition monosyllabic (EDA) & $\mathrm{DA}=6$ years \\
\hline $\begin{array}{l}\text { Suppression of the last phonem } \\
\text { (EDA) }\end{array}$ & $\mathrm{DA}=9$ years \\
\hline \multicolumn{2}{|l|}{ Semantic } \\
\hline Lexical reception (EDA) & $\mathrm{DA}=9$ years \\
\hline Picture designation (EVIP) & $\mathrm{DA}=13$ years \\
\hline Picture denomination (EDA) & $\mathrm{DA}=9$ years \\
\hline Semantic fluency (DEN 48) & - 1.9 SD compared to $8^{\text {th }}$ grade sample \\
\hline \multicolumn{2}{|l|}{ Morphosyntax } \\
\hline Syntax understanding (EDA) & $\mathrm{DA}=9$ years \\
\hline Sentence completure (EDA) & $\mathrm{DA}=9$ years \\
\hline \multicolumn{2}{|l|}{ Reading } \\
\hline Reading words in 1 min (LUM) & - 1.6 SD compared to $2^{\text {nd }}$ grade sample \\
\hline Reading text & $\mathrm{DA}=6$ years \\
\hline \multicolumn{2}{|l|}{ Writing } \\
\hline Figure copy (L2MA2) & - 1 ET compared to $6^{\text {th }}$ grade sample \\
\hline Text transcription & $\mathrm{DA}=6$ years \\
\hline
\end{tabular}

EDA, Examen des Dyslexies Acquises; EVIP, Échelle de vocabulaire en images Peabody; DEN 48, Epreuve de dénomination pour enfants; LUM, Lecture en Une Minute; L2MA2, spoken language, written language, memory, attention.

speech therapy was explained to the parents. Collaboration with social services was of main importance in this hospitalization. $\mathrm{He}$ was accompanied to a juvenile court session where a placement decision was set up. During the last week of the hospitalization, he visited a new residential care facility.
A major clinical improvement was observed during the hospitalization with a decrease in the behavior problems. At discharge, B no longer presented diagnostic criteria for IGD, and no specific intervention was required. Six months later, B no longer presented clinical or functional impairment.

\section{CLINICAL RELEVANCE}

\section{Interplay Between Disruptive Behaviors and Gaming Misuse}

We found in this vignette a relation between disruptive behaviors and gaming misuse in line with preexisting literature in adolescents $(4,8,10,11,15)$. A Spanish study showed that disruptive behavioral disorder was the most frequent diagnosis associated with IGD in a clinical sample of youths (15). It seems that IGD is associated with both proactive and reactive (impulsive) types of aggressive behaviors in adolescents. Wartberg et al. (10) found that in a large community-based sample of adolescents, those who self-reported symptoms for IGD were more prone to anger control problems, antisocial behavior, and SDQ hyperactivity/ inattention subscale, in multivariate analysis.

\section{Insecure Attachment, Emotional Dysregulation, and Impulsivity}

The description of patient B's usual way of dealing with emotional stressors since his early childhood was strongly evocative of an anxious-resistant subtype of attachment disorder (also called ambivalent attachment). Children with an anxious-resistant subtype of attachment disorder exhibit a high level of distress on separation and tend to be ambivalent when his/her caregiver returns (27). In middle childhood, these children are more likely to adopt "controlling" behavior (i.e., role-reversed) on caregivers. The displays of anger or helplessness towards the caregiver on reunion have been regarded as a strategy for maintaining the availability of the caregiver by preemptively taking control of the interaction (36).

A persistent lack of predictability of the caregiver's responses, such as found in B's family, did not allow children to develop reliable expectations about adults' behaviors. As a consequence, these children did not develop a proper sense of trust in their own ability to interpret their social world: they have, in general, more difficulties to accurately anticipate and interpret emotional cues (e.g., facial expression) and to understand their own mental state (37).

The fact that these children are immersed in a social world unintelligible to them and have more difficulties to stay "attuned" to others' emotional state explained the difficulties to develop optimal emotional regulation strategies and the myriad of associated behavioral problems (e.g., oppositional behavior, poor tolerance to frustration, temper tantrums, impulsive aggressive behaviors, peer rejection) $(29,36)$.

A low level of emotional regulation skills in childhood is a significant risk factor for behavioral addictive disorders in adolescents, including GD and Internet-related disorders (11, $22,23,32)$. Youths with difficulties to regulate their emotions 
could engage in such repeated behaviors to avoid or regulate negative feelings and emotions or to prolong positive emotional states (38). In the Discussion, we explain how poor emotional regulation strategies could represent both shared vulnerability factors and mediators of the relation between psychopathology and gaming misuse in the patient.

\section{DISCUSSION}

\section{Internalized Pathway to Gaming Misuse}

We present in Figure 1 a comprehensive view of the relation between risk and maintaining factors for video gaming misuse for patient $\mathrm{A}$. We hypothesized that a) the anxious-avoidant insecure attachment style as an infant, b) the internalized symptoms in childhood, and c) the persistent depressive disorder in early adolescence were distinct behavioral expressions of a common developmental pathway for liability for anxiety/mood disorders. In a context of individual vulnerability and poorly adjusted environment, our patient had through childhood poorly effective coping strategies to manage emotional distress. During adolescence, familial adverse events (loss of paternal support, maternal depression) and the difficulties with peer relationships made it more difficult for him to turn to a peer group to establish a new sense of identity and intimacy.

Gaming can be regarded here as a maladaptive coping strategy to avoid interpersonal relationships seen as frightening or unpredictable, while our patient favors the immediate gratification of gaming as an attachment alternative to relationships. To paraphrase Flores (39), gaming acts "as both an obstacle to and a substitute for interpersonal relationships." In turn, excessive gaming results and its relational consequences both worsen self-esteem and fuel depressive mood. The combination of gaming-related positive expectancies and behavioral/emotional avoidance for the development of IGD seems likely in this context as has been shown among adults (40).

\section{Externalized Pathway to Gaming Misuse}

We present in Figure 2 a distinct developmental pathway leading to gaming misuse. We hypothesized that a) school difficulties, especially in a context of learning disabilities, and b) environmental adversity, including lack of parental support and parental supervision, were important precipitating risk factors for both externalizing behaviors and gaming misuse. While cognitive difficulties such as delay in executive function development had existed since preschool age, its impact in terms of socio-emotional abilities may worsen with age in a context of increasing social and academic expectations. It is very likely that the difficulties in cognitive and motor inhibition to delay immediate reward generated multiple stressful situations (e.g., in school, in family) that fueled the patient's feeling of distress, frustration, and resent leading to "developmental cascades" (41). In adult literature such difficulties seem underpinned with abnormal prefrontal activities during the resting state (42) and delay tasks (43).

Early environmental or genetic factors that affect neurological and cognitive maturation may play roles in the emergence of psychopathology and gaming use problematic in this vignette. Firstly, genetic factors could be implied given that B's father was diagnosed with alcohol use disorder and the overlap between the genetic factors associated with behavioral and substance-related addictions (44). Secondly, fetal alcohol exposure may have interfered with B's developing central nervous system leading to suboptimal prefrontal cognitive activities and thus to faulty inhibitory control. Thirdly, early traumatic experiences and emotional neglect could also contribute to impede neurological maturation and cognitive abilities (45).

In this case report, we may hypothesize that B's compulsive search for an object of immediate pleasure through gaming may have resulted from maladaptive self-regulation strategies in a context where other forms of emotional self-regulation strategies (e.g., cognitive appraisal, seeking support) are inefficient. Using

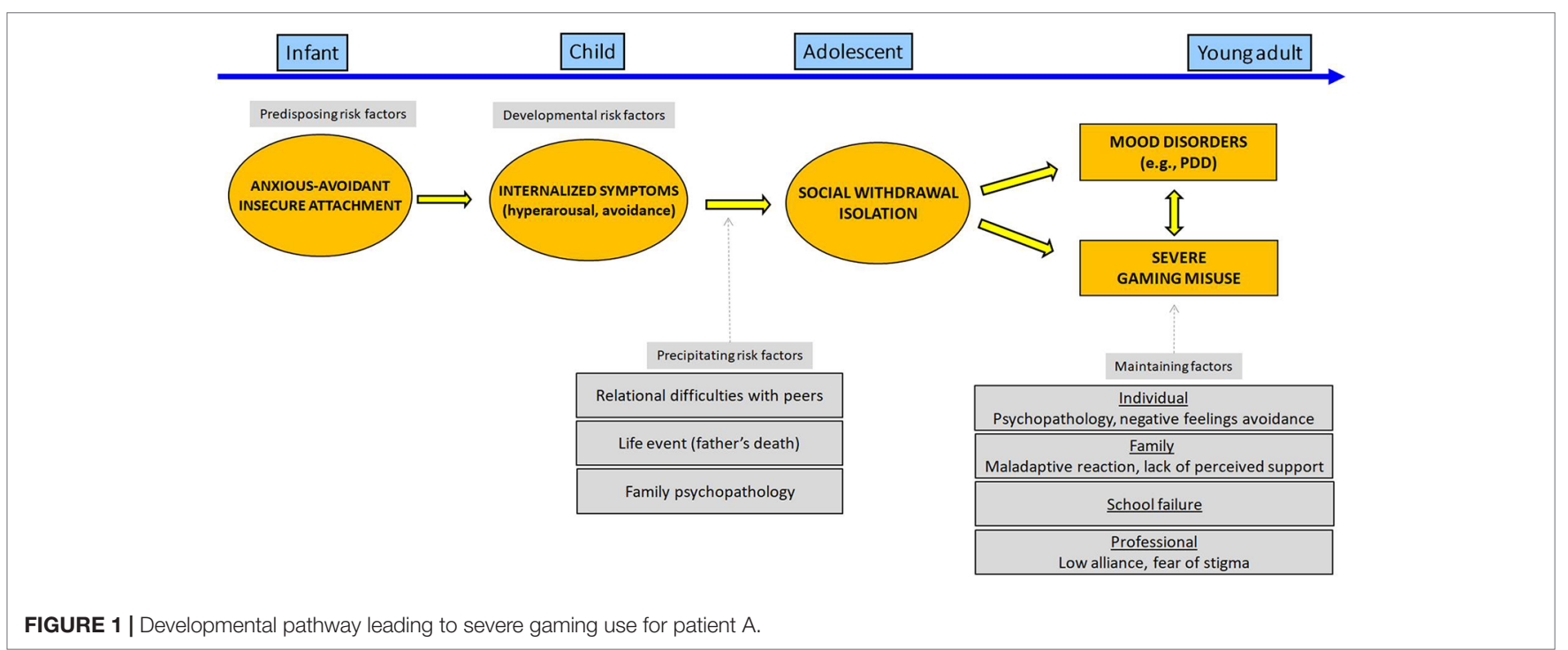




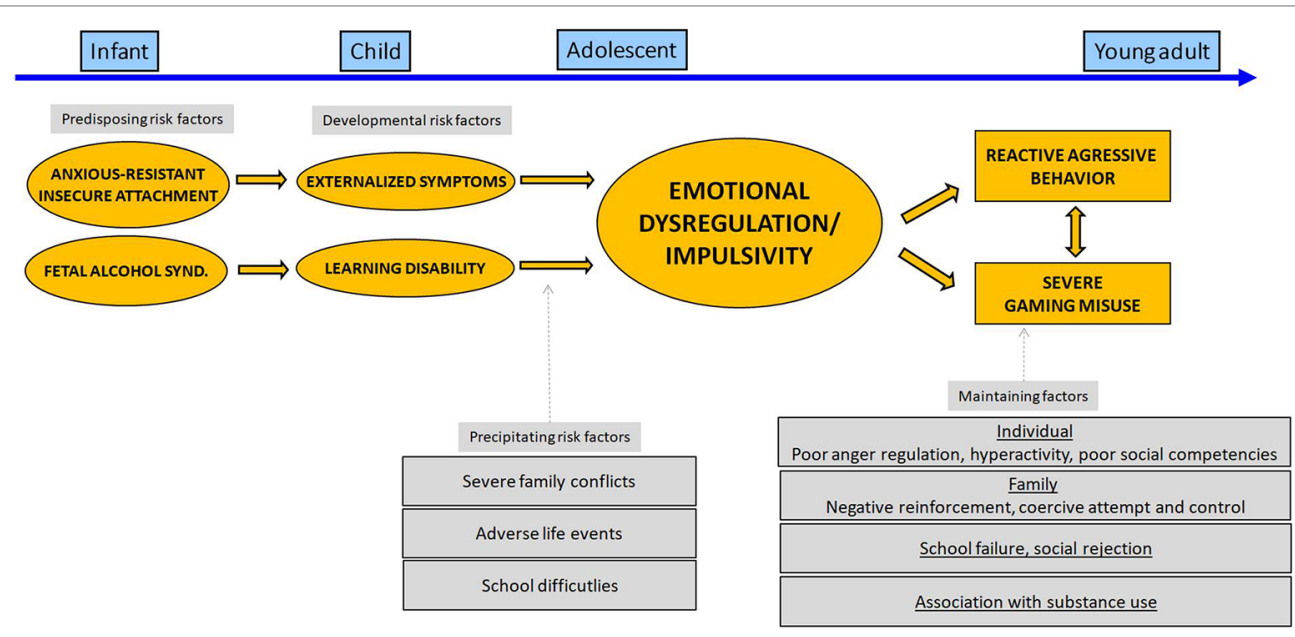

FIGURE 2 | Developmental pathway leading to severe gaming use for patient B.

a psychodynamic view, gaming behavior can be regarded as a substitute for other common sources of pleasure at this age at an object level (e.g., poor family and peer relationship) and a narcissistic level (low self-gratification in a context of failure/poor academic or educational performance) $(46,47)$. The limitation of B's affective domain to gaming may be partly explained by the necessity to restrict possible sources of pleasure/displeasure to limited and thus predictable factors in his environment. The rules of the video game are probably easily understandable for B and viewed as more "fair" than external rules.

\section{Clinical and Research Implications}

A's difficulties to recognize his own feelings and express conflicting views about care, usual for adolescents with attachment issues, complicate therapeutic relationships and treatment plan adhesion (48). A low level of treatment motivation and readiness to change are regarded as the main reasons for the lack of effectiveness of psychotherapy in adolescents with IGD $(49,50)$. Insight-oriented psychotherapies may be of main interest for adolescents with IGD such as attachment-based psychotherapy (20), mentalizingbased psychotherapy (51), and dialectical-behavioral therapy (52). Such approaches promote patient emotional awareness and expression (e.g., for A) or gaining a sense of trust in relationships (e.g., for B) that contribute to an increased proneness for multiple co-occurring addictions (53).

What is the role of hospitalization in this context? A's separation from his usual environment helped him to break out of the accustomed pattern of excessive gaming, but a relapse occurred shortly after hospital discharge. Hospitalization of adolescents with behavioral addiction is not only an opportunity to stop the maladaptive behavior but also to improve the adolescent's and his/her family's knowledge about the internal and external maintaining risk factors (54). As shown here, the attachment issue is frequently associated with family factors for IGD that could deserve targeted interventions: parental depression (55), parental anxiety (10), poor level of perceived family support (56), or parental insecure attachment $(32,33)$.

Some have suggested that family difficulties may have a more causative role in the emergence of IGD in adolescents. Young people with problematic Internet use had greater disapproval of their families and perceived their parents as less supportive and warm when compared with young people with no problematic Internet use (57). Xu et al. (58) found in a sample of 5,122 adolescents that the quality of parent-adolescent relationship and communication was closely associated with the development of adolescent Internet addiction. For Lam (55), Internet misuse could be seen as an attempt to compensate problematic interactions with one parent, especially in case of parental psychopathology. In a context of severe emotional neglect, as in B's family, video gaming seems to be one of the only stable and predictable sources of pleasure in a family where adults were poorly involved and available for their children.

Finally, as illustrated in these two clinical cases, careful assessment of environmental backgrounds and developmental history is of major importance to find ongoing stressful factors that fuel the patient's psychopathology and/or maladaptive emotional regulation strategies. Youths with multiple specific learning disabilities may represent a very high risk population for IGD considering the multiple risk factors for gaming misuse, e.g., academic failure, lower socio-emotional competencies, and delay in executive function development.

\section{CONCLUSION}

We stress the need to consider the developmental pathways underlying the association between psychopathology and/ or gaming misuse in youths with IGD. An "internalized" and "externalized" pathway to gaming misuse via the onset of distinct, but somewhat overlapping, psychiatric disorders and environmental factors is presented in Figures $\mathbf{1}$ and $\mathbf{2}$. 
Gaming behaviors may be seen as specific forms of maladaptive self-regulatory strategies in youths with attachment issues. Considering underlying vulnerability factors, such as insecure attachment style and emotional dysregulation, may represent an important therapeutic opportunity for youths with dual disorders.

\section{AUTHOR CONTRIBUTIONS}

$\mathrm{XB}$ and DC performed substantial contributions to the conception and design of the work. XB, PM, CI, and HM performed substantial contributions to the acquisition, analysis, or interpretation of data. XB drafted the work or revised it critically for important intellectual content. XB, PM, YE, DC, CI,

\section{REFERENCES}

1. American Psychiatric Association. Diagnostic and statistical manual of mental disorders. 5th edition. American Psychiatric Association (2013). doi: 10.1176/appi.books.9780890425596

2. World Health Organization. International Classification of Diseases, 11th Revision (ICD-11) - 6C51 Gaming disorder [Online] (2018). Available: https:// icd.who.int/browse11/l-m/en\#/http://id.who.int/icd/entity/1448597234 [Accessed].

3. Gentile DA, Bailey K, Bavelier D, Brockmyer JF, Cash H, Coyne SM, et al. Internet gaming disorder in children and adolescents. Pediatrics (2017) 140:S81-S85. doi: 10.1542/peds.2016-1758H

4. Király O, Griffiths MD, Demetrovics Z. Internet gaming disorder and the DSM-5: conceptualization, debates, and controversies. Curr Addict Rep (2015) 2:254-62. doi: 10.1007/s40429-015-0066-7

5. Kardefelt-Winther D. Conceptualizing Internet use disorders: addiction or coping process? Psychiatry Clin Neurosci (2017) 71:459-66. doi: 10.1111/ pcn. 12413

6. Kuss DJ, Griffiths MD, Pontes HM. Chaos and confusion in DSM-5 diagnosis of Internet gaming disorder: issues, concerns, and recommendations for clarity in the field. J Behav Addict (2017) 6:103-9. doi: 10.1556/2006.5.2016.062

7. Quandt T. Stepping back to advance: why IGD needs an intensified debate instead of a consensus. J Behav Addict (2017) 6:121-3. doi: 10.1556/2006.6.2017.014

8. Lemmens JS, Valkenburg PM, Gentile DA. The Internet gaming disorder Scale. Psychol Assess (2015) 27:567-82. doi: 10.1037/pas0000062

9. King DL, Delfabbro PH. The cognitive psychopathology of Internet gaming disorder in adolescence. J Abnorm Child Psychol (2016) 44:1635-45. doi: 10.1007/s10802-016-0135-y

10. Wartberg L, Brunner R, Kriston L, Durkee T, Parzer P, Fischer-Waldschmidt $\mathrm{G}$, et al. Psychopathological factors associated with problematic alcohol and problematic Internet use in a sample of adolescents in Germany. Psychiatry Res (2016) 240:272-7. doi: 10.1016/j.psychres.2016.04.057

11. Yu H, Cho J. Prevalence of Internet gaming disorder among Korean adolescents and associations with non-psychotic psychological symptoms, and physical aggression. Am J Health Behav (2016) 40:705-16. doi: 10.5993/ AJHB.40.6.3

12. Pontes HM. Investigating the differential effects of social networking site addiction and Internet gaming disorder on psychological health. J Behav Addict (2017) 6:601-10. doi: 10.1556/2006.6.2017.075

13. Sioni SR, Burleson $\mathrm{MH}$, Bekerian DA. Internet gaming disorder: social phobia and identifying with your virtual self. Comput Hum Behav (2017) 71:11-5. doi: 10.1016/j.chb.2017.01.044

14. Bozkurt H, Coskun M, Ayaydin H, Adak I, Zoroglu SS. Prevalence and patterns of psychiatric disorders in referred adolescents with Internet addiction. Psychiatry Clin Neurosci (2013) 67:352-9. doi: 10.1111/pcn.12065

15. Martin-Fernandez M, Matali JL, Garcia-Sanchez S, Pardo M, Lleras M, Castellano-Tejedor C. Adolescents with Internet gaming disorder (IGD): and $\mathrm{HM}$ gave the final approval of the version to be published. $\mathrm{XB}, \mathrm{PM}, \mathrm{YE}, \mathrm{DC}, \mathrm{CI}$, and HM agreed to be accountable for all aspects of the work in ensuring that questions related to the accuracy or integrity of any part of the work are appropriately investigated and resolved.

\section{FUNDING}

We sincerely thank the institutions that have financially supported this project: la Direction General de la Santé (DGS), la Caisse Nationale de l'Assurance Maladie des Travailleurs Salariés (CNAMTS), la Mission interministérielle de lutte contre les droguesetlesconduitesaddictives (MILDECA), andl'Observatoire national des Jeux (ODJ) (“IReSP-15-Prevention-11").

profiles and treatment response. Adicciones (2016) 29:125-33. doi: 10.20882/ adicciones. 890

16. Gentile DA, Choo H, Liau A, Sim T, Li D, Fung D, et al. Pathological video game use among youths: a two-year longitudinal study. Pediatrics (2011) 127:e319-29. doi: 10.1542/peds.2010-1353

17. Brunborg GS, Mentzoni RA, Froyland LR. Is video gaming, or video game addiction, associated with depression, academic achievement, heavy episodic drinking, or conduct problems? J Behav Addict (2014) 3:27-32. doi: 10.1556/JBA.3.2014.002

18. Wartberg L, Kriston L, Zieglmeier M, Lincoln T, Kammerl R. A longitudinal study on psychosocial causes and consequences of Internet gaming disorder in adolescence. Psychol Med (2018) 49(2):1-8. doi: 10.1017/S003329171800082X

19. Davidson LL, Grigorenko EL, Boivin MJ, Rapa E, Stein A. A focus on adolescence to reduce neurological, mental health and substance-use disability. Nature (2015) 527:S161-6. doi: 10.1038/nature16030

20. Padykula NL, Conklin P. The self regulation model of attachment trauma and addiction. Clin Social Work J (2010) 38:351-60. doi: 10.1007/ s10615-009-0204-6

21. Schindler A, Thomasius R, Sack PM, Gemeinhardt B, Kustner U. Insecure family bases and adolescent drug abuse: a new approach to family patterns of attachment. Attach Hum Dev (2007) 9:111-26. doi: 10.1080/14616730701349689

22. Iacono WG, Malone SM, Mcgue M. Behavioral disinhibition and the development of early-onset addiction: common and specific influences. Annu Rev Clin Psychol (2008) 4:325-48. doi: 10.1146/annurev. clinpsy.4.022007.141157

23. Starcevic V, Khazaal Y. Relationships between behavioural addictions and psychiatric disorders: what is known and what is yet to be learned? Front Psychiatry (2017) 8:53. doi: 10.3389/fpsyt.2017.00053

24. Gwynette MF, Sidhu SS, Ceranoglu TA. Electronic screen media use in youth with autism spectrum disorder. Child Adolesc Psychiatr Clin N Am (2018) 27:203-19. doi: 10.1016/j.chc.2017.11.013

25. Benarous X, Edel Y, Consoli A, Brunelle J, Etter JF, Cohen D, et al. Ecological momentary assessment and smartphone application intervention in adolescents with substance use and comorbid severe psychiatric disorders: study protocol. Front Psychiatry (2016) 7:157. doi: 10.3389/fpsyt.2016.00157

26. Gagnier JJ, Kienle G, Altman DG, Moher D, Sox H, Riley D. The CARE Guidelines: consensus-based clinical case reporting guideline development. Glob Adv Health Med (2013) 2:38-43. doi: 10.7453/gahmj.2013.008

27. Ainsworth MD, Bell SM. Attachment, exploration, and separation: illustrated by the behavior of one-year-olds in a strange situation. Child Dev (1970) 41:49-67. doi: 10.1111/j.1467-8624.1970.tb00975.x

28. Main M. The ultimate causation of some infant attachment phenomena: further answers, further phenomena, and further questions. Behav Brain Sci (1979) 2:640-3. doi: 10.1017/S0140525X00064992

29. Thompson RA. Early attachment and later development: familiar questions, new answers. In: Cassidy J, Shaver PR, editors. Handbook of attachment, 2nd ed. Guilford (2008). p. 348-65. 
30. Schimmenti A, Passanisi A, Gervasi AM, Manzella S, Fama FI. Insecure attachment attitudes in the onset of problematic Internet use among late adolescents. Child Psychiatry Hum Dev (2014) 45:588-95. doi: 10.1007/s10578-013-0428-0

31. Schimmenti A, Bifulco A. Linking lack of care in childhood to anxiety disorders in emerging adulthood: the role of attachment styles. Child Adolesc Ment Health (2015) 20:41-8. doi: 10.1111/camh.12051

32. Estevez A, Jauregui P, Sanchez-Marcos I, Lopez-Gonzalez H, Griffiths MD. Attachment and emotion regulation in substance addictions and behavioral addictions. J Behav Addict (2017) 6:534-44. doi: 10.1556/2006.6.2017.086

33. Monacis L, De Palo V, Griffiths MD, Sinatra M. Exploring individual differences in online addictions: the role of identity and attachment. Int J Ment Health Addict (2017) 15:853-68. doi: 10.1007/s11469-017-9768-5

34. Throuvala MA, Janikian M, Griffiths MD, Rennoldson M, Kuss DJ. The role of family and personality traits in Internet gaming disorder: a mediation model combining cognitive and attachment perspectives. J Behav Addict (2019) 8(1):48-62. doi: 10.1556/2006.8.2019.05

35. Benarous X, Consoli A, Guile JM, Garny De La Riviere S, Cohen D, Olliac B. Evidence-based treatments for youths with severely dysregulated mood: a qualitative systematic review of trials for SMD and DMDD. Eur Child Adolesc Psychiatry (2017) 26:5-23. doi: 10.1007/s00787-016-0907-5

36. Solomon J, George C, De Jong A. Children classified as controlling at age six: evidence of disorganized representational strategies and aggression at home and at school. Dev Psychopathol (1995) 7:447-63. doi: 10.1017/S0954579400006623

37. Sroufe LA, Egeland B, Kreutzer T. The fate of early experience following developmental change: longitudinal approaches to individual adaptation in childhood. Child Dev (1990) 61:1363-73. doi: 10.1111/j.1467-8624.1990.tb02867.x

38. Aldao A, Nolen-Hoeksema S, Schweizer S. Emotion-regulation strategies across psychopathology: a meta-analytic review. Clin Psychol Rev (2010) 30:217-37. doi: 10.1016/j.cpr.2009.11.004

39. Flores PJ. Conflict and repair in addiction treatment. J Groups Addict Recovery (2006) 1:5-26. doi: 10.1300/J384v01n01_02

40. Laier C, Wegmann E, Brand M. Personality and cognition in gamers: avoidance expectancies mediate the relationship between maladaptive personality traits and symptoms of Internet-gaming disorder. Front Psychiatry (2018) 9:304. doi: 10.3389/fpsyt.2018.00304

41. Masten AS, Roisman GI, Long JD, Burt KB, Obradovic J, Riley JR, et al. Developmental cascades: linking academic achievement and externalizing and internalizing symptoms over 20 years. Dev Psychol (2005) 41:733-46. doi: 10.1037/0012-1649.41.5.733

42. Kuss DJ, Pontes HM, Griffiths MD. Neurobiological correlates in Internet gaming disorder: a systematic literature review. Front Psychiatry (2018) 9:166. doi: 10.3389/fpsyt.2018.00166

43. Wang Y, Hu Y, Xu J, Zhou H, Lin X, Du X, et al. Dysfunctional prefrontal function is associated with impulsivity in people with Internet gaming disorder during a delay discounting task. Front Psychiatry (2017) 8:287. doi: $10.3389 /$ fpsyt.2017.00287

44. Yau YH, Potenza MN. Gambling disorder and other behavioral addictions: recognition and treatment. Harv Rev Psychiatry (2015) 23:134-46. doi: 10.1097/HRP.0000000000000051

45. Schore AN. The effects of early relational trauma on right brain development, affect regulation, and infant mental health. Infant Ment Health J(2001) 22:20169. doi: 10.1002/1097-0355(200101/04)22:1<201::AID-IMHJ8>3.0.CO;2-9
46. Erikson EH. Identity: Youth and Crisis. New York: WW Norton \& Company (1994).

47. Moccia L, Mazza M, Di Nicola M, Janiri L. The Experience of pleasure: a perspective between neuroscience and psychoanalysis. Front Hum Neurosci (2018) 12:359. doi: 10.3389/fnhum.2018.00359

48. Jaunay E, Consoli A, Greenfield B, Guile JM, Mazet P, Cohen D. Treatment refusal in adolescents with severe chronic illness and borderline personality disorder. J Can Acad Child Adolesc Psychiatry (2006) 15:135-42.

49. O'brien JE, Li W, Snyder SM, Howard MO. Problem Internet overuse behaviors in college students: readiness-to-change and receptivity to treatment. J Evid Inf Soc Work (2016) 13:373-85. doi: 10.1080/23761407.2015.1086713

50. Lindenberg K, Szász-Janocha C, Schoenmaekers S, Wehrmann U, Vonderlin E. An analysis of integrated health care for Internet use disorders in adolescents and adults. J Behav Addict (2017) 6:579-92. doi: 10.1556/2006.6.2017.065

51. Asen E, Fonagy P. Mentalization-based therapeutic interventions for families. J Fam Ther (2012) 34:347-70. doi: 10.1111/j.1467-6427.2011.00552.x

52. Bernheim D, Gander M, Keller F, Becker M, Lischke A, Mentel R, et al. The role of attachment characteristics in dialectical behavior therapy for patients with borderline personality disorder. Clin Psychol Psychother (2019). In press. doi: $10.1002 /$ cpp. 2355

53. Di Nicola M, Ferri VR, Moccia L, Panaccione I, Strangio AM, Tedeschi D, et al. Gender differences and psychopathological features associated with addictive behaviors in adolescents. Front Psychiatry (2017) 8:256-6. doi: $10.3389 /$ fpsyt.2017.00256

54. Gioka S, Kefaliakos A, Ioannou A, Mechili A, Diomidous M. Hospital based treatment for Internet addicts. Stud Health Technol Inform (2014) 202:27982. doi: 10.3233/978-1-61499-423-7-279

55. Lam LT. Parental mental health and Internet addiction in adolescents. Addict Behav (2015) 42:20-3. doi: 10.1016/j.addbeh.2014.10.033

56. Schneider LA, King DL, Delfabbro PH. Family factors in adolescent problematic Internet gaming: a systematic review. J Behav Addict (2017) 6:321-33. doi: 10.1556/2006.6.2017.035

57. Li X, Li D, Newman J. Parental behavioral and psychological control and problematic internet use among Chinese adolescents: the mediating role of self-control. Cyberpsychol Behav Soc Netw (2013) 16:442-7. doi: 10.1089/ cyber.2012.0293

58. Xu J, Shen LX, Yan CH, Hu H, Yang F, Wang L, et al. Parent-adolescent interaction and risk of adolescent internet addiction: a population-based study in Shanghai. BMC Psychiatry (2014) 14:112. doi: 10.1186/1471-244X-14-112

Conflict of Interest Statement: The research was conducted in the absence of any commercial or financial relationships that could be construed as a potential conflict of interest.

Copyright (C) 2019 Benarous, Morales, Mayer, Iancu, Edel and Cohen. This is an open-access article distributed under the terms of the Creative Commons Attribution License (CC BY). The use, distribution or reproduction in other forums is permitted, provided the original author(s) and the copyright owner(s) are credited and that the original publication in this journal is cited, in accordance with accepted academic practice. No use, distribution or reproduction is permitted which does not comply with these terms. 